\title{
Sodium transport system in plant cells
}

\section{Toshio Yamaguchi $^{1}{ }^{*}$, Shin Hamamoto ${ }^{2}$ and Nobuyuki Uozumi ${ }^{2}$}

' Department of Microbiology, Faculty of Pharmacy, Niigata University of Pharmacy and Applied Life Sciences, Niigata, Japan

2 Department of Biomolecular Engineering, Graduate School of Engineering, Tohoku University, Sendai, Japan

\author{
Edited by: \\ Yuriko Osakabe, RIKEN Plant Science \\ Center, Japan

\section{Reviewed by:} \\ Quan-Sheng Qiu, Lanzhou University, \\ China \\ Hannetz Roschzttardtz, University of \\ Wisconsin-Madison, USA

\section{*Correspondence:} \\ Toshio Yamaguchi, Department of \\ Microbiology, Faculty of Pharmacy, \\ Niigata University of Pharmacy and \\ Applied Life Sciences, 265-1 \\ Higashijima, Akiha-ku, Niigata-shi, \\ Niigata 956-8603, Japan \\ e-mail:yamaguchi@nupals.ac.jp
}

Since sodium, $\mathrm{Na}$, is a non-essential element for the plant growth, the molecular mechanism of $\mathrm{Na}^{+}$transport system in plants has remained elusive for the last two decades. The accumulation of $\mathrm{Na}^{+}$in soil through irrigation for sustainable agricultural crop production, particularly in arid land, and by changes in environmental and climate conditions leads to the buildup of toxic level of salts in the soil. Since the latter half of the twentieth century, extensive molecular research has identified several classes of $\mathrm{Na}^{+}$transporters that play major roles in the alleviation of ionic stress by excluding toxic $\mathrm{Na}^{+}$from the cytosol or preventing $\mathrm{Na}^{+}$transport to the photosynthetic organs, and also in osmotic stress by modulating intra/extracellular osmotic balance. In this review, we summarize the current knowledge of three major $\mathrm{Na}^{+}$transporters, namely NHX, SOS1, and HKT transporters, including recently revealed characteristics of these transporters.

Keywords: salt tolerance, $\mathrm{Na}^{+}$transporter, plant, $\mathrm{NHX}$ transporters, SOS1 transporters, $\mathrm{HKT}$ transporters

\section{INTRODUCTION}

Water availability and its quality greatly affect the growth of most of plant species, and keeping a sufficient amount of water in the soil is of paramount importance for agricultural crop production. Constant irrigation often leads to the accumulation of undesirable salts due to the use of poor quality water, particularly in arid lands, and it has been estimated that about $20 \%$ of irrigated land is affected by soil salinity (Yeo, 1999). Salinity stress to most plant species mainly accounts for the increase in cytoplasmic osmotic stress and ion (mainly $\mathrm{Na}^{+}$)-specific toxicity (Blumwald, 2000; Blumwald et al., 2000 Munns and Tester, 2008). Overaccumulation of $\mathrm{Na}^{+}$in the cytosol causes inhibitions of protein synthesis, many enzymatic reactions (Hall and Flowers, 1973; Flowers and Läuchli, 1983; Murguía et al., 1995), and photosynthetic processes (Tsugane et al., 1999; Tsunekawa et al., 2009). Exclusion of $\mathrm{Na}^{+}$ from photosynthetic organs is therefore crucial for the maintenance of an adequate metabolism and efficient carbon fixation.

To date, several classes of $\mathrm{Na}^{+}$-transporters have been shown to play central roles in $\mathrm{Na}^{+}$homeostasis during salinity stress (Apse and Blumwald, 2007; Hauser and Horie, 2010; Uozumi and Schroeder, 2010). Among them, the NHX-, SOS1-, and the Class I HKT-type transporter have drawn particular attention because of their capability of transporting $\mathrm{Na}^{+}$across cellular membranes (Figure 1). Many studies have demonstrated significant involvements of these $\mathrm{Na}^{+}$transporters in $\mathrm{Na}^{+}$sequestration in plant vacuoles, $\mathrm{Na}^{+}$extrusion from cells, and $\mathrm{Na}^{+}$circulation for the alleviation of sodium stress under saline conditions. Moreover, some of these $\mathrm{Na}^{+}$transporters have been shown to improve salinity tolerance of crop plants when their encoding gene is overexpressed (Yamaguchi and Blumwald, 2005; Agarwal et al., 2013).

In this review, we will provide brief summaries on the properties and physiological roles of three major $\mathrm{Na}^{+}$transporters that are involved in the plant $\mathrm{Na}^{+}$tolerance, namely NHX, SOS1, and HKT transporters, from well-established to recently revealed characteristics of these transporters.

\section{NHX TRANSPORTERS}

One of the strategies that plant cells employ for the alleviation of excess cytosolic $\mathrm{Na}^{+}$is to compartmentalize $\mathrm{Na}^{+}$into the vacuoles, and NHX-type intracellular $\mathrm{Na}^{+} / \mathrm{H}^{+}$exchangers have appeared to be the best-characterized proteins involved in this process so far (Blumwald et al., 2000). Most of NHX proteins studied to date mediate electroneutral $\mathrm{Na}^{+} / \mathrm{H}^{+}$and $\mathrm{K}^{+} / \mathrm{H}^{+}$antiport across the membrane by utilizing the $\mathrm{H}^{+}$gradient as a driving force and are considered to be responsible for $\mathrm{Na}^{+}$sequestration into intracellular compartments under salinity stress (Bassil et al., 2012).

Plant genomes often contain multiple intracellular NHX isoforms (Bassil etal., 2012). Intracellular NHX transporters are classified into the IC-NHE/NHX family (Pardo et al., 2006), which is a part of the large cation/proton antiporter 1 (CPA1) family (Säier etal., 2006). These are further subdivided into vacuolar (Class I) or endosomal (Class II) NHXs, according to their sequence similarity and subcellular localizations of representative members (Rodríguez-Rosales et al., 2009; Bassil et al., 2012; Figure 1). Most of the plant species sequenced to date contain both types of NHXs (Rodríguez-Rosales et al., 2009; Bassil et al., 2012), and functional redundancies of vacuolar or endosomal NHXs had been recently reported in Arabidopsis (Bassil et al., 2011a,b; Barragan et al., 2012).

Currently, two distinct topology models have been proposed for AtNHX1. The first model was proposed based on the protease protection analysis of isolated yeast vacuoles expressing full-length AtNHX1 with epitope tags inserted into each hydrophilic loop (Yamaguchi et al., 2003). This model comprised nine transmembrane segments with a C-terminal hydrophilic tail facing toward the vacuolar lumen. Another topology model was proposed on the 


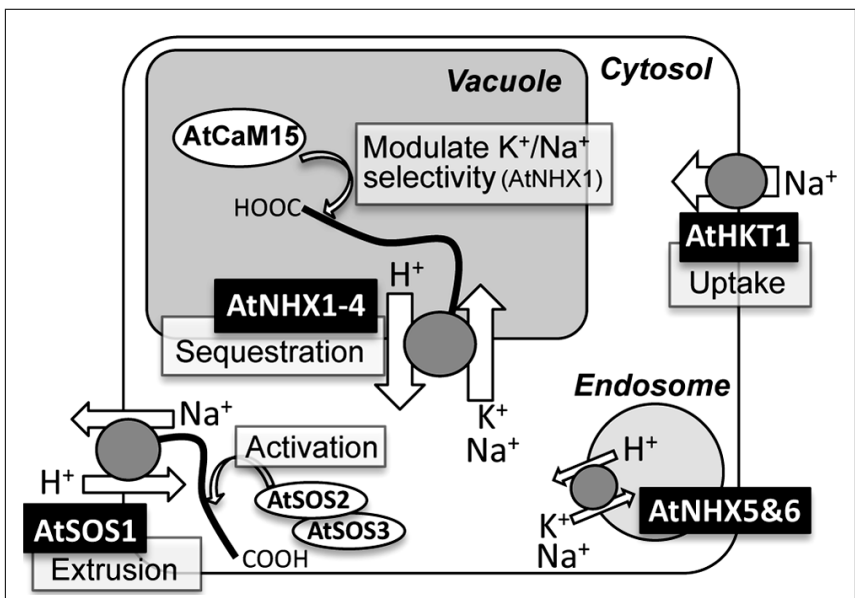

FIGURE 1 | Schematic representation of subcellular localizations, functions, and regulations of NHX-, SOS1-, and HKT1-type $\mathrm{Na}^{+}$ transporters in Arabidopsis. basis of in vitro translation experiments using truncated AtNHX1 genes, which suggested that several transmembrane segments of AtNHX1 retain similar topogenic properties as human NHE1 (Sato and Sakaguchi, 2005).

The cation selectivity of AtNHX1 appears to be regulated by its C-terminal tail through the binding to a calmodulin-like protein AtCaM15, which interacts with the C-terminus of AtNHX1 in a $\mathrm{Ca}^{2+}$ and $\mathrm{pH}$ dependent manner from inside of the vacuole (Yamaguchi et al., 2005; Figure 1). Interaction with AtCaM15 decreases the $\mathrm{Na}^{+}$transport activity of AtNHX1, while keeping $\mathrm{K}^{+}$ transport activity almost unchanged. Given that the plant vacuole usually keeps a high $\mathrm{Ca}^{2+}$ concentration and an acidic luminal $\mathrm{pH}$, AtNHX1 would favor a $\mathrm{K}^{+} / \mathrm{H}^{+}$antiport mode under normal physiological conditions due to the binding with AtCaM15. However, under salinity stress, which often causes vacuolar alkalization (Okazaki et al., 1996; Gruwel et al., 2001), disassociation of AtCaM15 would result in increased $\mathrm{Na}^{+} / \mathrm{H}^{+}$antiport activity of AtNHX1 and promote compartmentation of $\mathrm{Na}^{+}$into the vacuoles (Yamaguchi et al., 2005).

Overexpression of genes encoding vacuolar NHXs has conferred salt tolerance to a range of plant species with a concomitant increase in tissue $\mathrm{Na}^{+}$(Apse et al., 1999; Zhang and Blumwald, 2001; Zhang et al., 2001; Agarwal et al., 2013). These observations, together with the fact that the Arabidopsis atnhx1 mutant exhibited $\mathrm{Na}^{+}$sensitivity and significantly less vacuolar $\mathrm{Na}^{+} / \mathrm{H}^{+}$antiport activity (Apse et al., 2003), strongly supported the role of vacuolar NHXs in $\mathrm{Na}^{+}$compartmentation under salinity stress. However, there has been a case where the overexpression of vacuolar NHX led to accumulations of $\mathrm{K}^{+}$but not $\mathrm{Na}^{+}$(Leidi et al., 2010). Involvement of endosomal NHXs in salt tolerance has also been demonstrated in tomato and Arabidopsis. LeNHX2 knockdown tomato and atnhx5/atnhx6 double knockout Arabidopsis plants exhibited salt sensitivities (Rodríguez-Rosales et al., 2008; Bassil et al., 2011a). The introduction of the AtNHX5 gene increased salt tolerance and $\mathrm{Na}^{+}$-accumulation in Torenia (Shi et al., 2008). Tomato plants overexpressing LeNHX2 also showed increased salt tolerance. However, an increase of tissue $\mathrm{K}^{+}$instead of $\mathrm{Na}^{+}$was observed in this case, suggesting that increased salt tolerance was achieved by improving cellular $\mathrm{K}^{+}$-homeostasis (Huertas et al., 2013).

Besides significant roles in salt tolerance, involvement in $\mathrm{pH}$ regulation has been demonstrated for vacuolar NHXs (Fukada-Tanaka et al., 2000; Yamaguchi et al., 2001). Furthermore, vacuolar NHXs appeared to be involved in organ developments. The Arabidopsis atnhx1/atnhx2 double knockout plant exhibited severe defects on the plant growth, development of reproductive organ, and leaf cell expansion under normal conditions (Bassil et al., 2011b; Barragan et al., 2012). These developmental defects seem to be attributed to the role of AtNHXs in $\mathrm{K}^{+}$- rather than $\mathrm{Na}^{+}$-homeostasis, since the $n h \times 1-1 / n h \times 2-1$ plant accumulated a lower level of $\mathrm{K}^{+}$and exhibited less tonoplast $\mathrm{K}^{+} / \mathrm{H}^{+}$antiport activity than the wild type plant. Severe growth defects have also been observed in endosomal NHX knockout/knockdown plants. The LeNHX2 knockdown tomato plant showed severely retarded growth as compared to the wild type (Rodríguez-Rosales et al., 2008). Similarly, Arabidopsis atnhx5/atnhx6 double knockout lines exhibited smaller cell size, slower development of flower organs, and root growth (Bassil etal., 2011a). These results may indicate significant contributions of endosomal NHXs on growth and development, possibly via maintaining appropriate $\mathrm{pH}$ and/or cation balance in plant cells. Roles in endosomal trafficking have also been documented (Sottosanto et al., 2004; Bassil et al., 2011a), which have been recently summarized in excellent review articles (Bassil et al., 2012; Qiu, 2012) and therefore will not be discussed further.

\section{SOS1 TRANSPORTERS}

Exclusion of $\mathrm{Na}^{+}$from the cytosol across the plasma membrane is also an important mechanism for the alleviation of cellular $\mathrm{Na}^{+}$ toxicity in plants (Blumwald, 2000). To date, the SOS1 (salt overly sensitive $1=$ AtNHX7 in Arabidopsis) transporters are the bestcharacterized class of transporters attributed with this function (Figure 1). The SOS1 gene has been identified in several plants including Arabidopsis (Wu et al., 1996), rice (Martínez-Atienza et al., 2007), wheat (Xu et al., 2008), tomato (Olías et al., 2009), and Thellungiella salsuginea (Vera-Estrella et al., 2005). The SOS1 gene encodes a large membrane protein $(127 \mathrm{kDa}$, in the case of Arabidopsis AtSOS1) that is categorized into the CPA1 family along with NHXs, although it is more closely related to bacterial NhaP antiporters (Wu et al., 1996; Shi et al., 2000; Brett et al., 2005). AtSOS1 protein is localized in the plasma membrane, and appears to mediate electroneutral $\mathrm{Na}^{+} / \mathrm{H}^{+}$antiport (Shi et al., 2002; Qiu et al., 2002, 2003). Hydropathy prediction has indicated that the AtSOS1 protein consists of 12 putative transmembrane segments and a long C-terminal hydrophilic tail (approximately 700 aa; Shi et al., 2000). Although detailed structural properties of AtSOS1 remain elusive, a recent biochemical analysis revealed that AtSOS1 forms a homodimer (Núñez-Ramírez et al., 2012). In addition, Arabidopsis has another SOS1-like gene, termed AtNHX8, which seems to encode a C-terminal truncated isoform of AtSOS1. Despite its high similarity to AtSOS1 ( $~ 88 \%$ for hydrophobic region), AtNHX8 seemed to prefer $\mathrm{Li}^{+}$over $\mathrm{Na}^{+}$as its substrate (An et al., 2007). 
It appears that the AtSOS1 C-terminus contains an activation and an auto-inhibitory domain that are physically associated to each other, and this interaction seems to suppress AtSOS1 activity at the resting state (Quintero etal., 2011). The activation of AtSOS1 occurs via the direct phosphorylation of the autoinhibitory domain by the serine/threonine kinase AtSOS2, which requires a calcium binding protein, AtSOS3, or SCaBP8/CBL10, for its kinase activity (Figure 1; Qiu et al., 2002; Quan et al., 2007; Quintero et al., 2011). In addition, AtSOS2 and AtSOS3 have also shown to be required for the $\mathrm{Na}^{+}$-dependent induction of AtSOS1 gene (Shi et al., 2000).

The physiological significance of SOS1 transporters in saline environments has been well established in Arabidopsis, tomato, and $T$. salsuginea, as significant increases in salt sensitivity has been observed for the knockout/knockdown plants of corresponding SOS1 genes (Wu et al., 1996; Shi et al., 2000, 2002; Oh et al., 2009; Olías et al., 2009). All of these knockout/knockdown plants tend to accumulate higher amounts of $\mathrm{Na}^{+}$than wild type plants under severe salt stress, revealing critical roles of SOS1 transporters in limiting $\mathrm{Na}^{+}$entry by promoting $\mathrm{Na}^{+}$efflux at the plasma membrane of the root cells (Shi etal., 2002; Oh et al., 2009; Olías et al., 2009). This is well in agreement with the observation that the AtSOS1 transcript is predominantly expressed in epidermal cells of the root tip (Shi et al., 2002), and that the overexpression of AtSOS1, T. salsuginea SOS1, and rice OsSOS1 in Arabidopsis successfully conferred resistance to salinity stress (Shi et al., 2003; Martínez-Atienza et al., 2007; Oh et al., 2009; Yang et al., 2009). Furthermore, SOS1 appears to play a role in protecting the root plasma membrane $\mathrm{K}^{+}$uptake under salinity stress (Qi and Spalding, 2004). Involvement in xylem loading of $\mathrm{Na}^{+}$ for root to shoot transport has also been suggested for AtSOS1 under moderate salt stress and low transpiration conditions (Ding and Zhu, 1997; Shi et al., 2002). This is based on the preferential expression of AtSOS1 in xylem parenchyma cells and decreased shoot $\mathrm{Na}^{+}$contents in the atsos 1 mutant than in wild type under hydroponic or high humidity conditions (Shi et al., 2002). On the other hand, SISOS1-silenced tomato (Solanum lycopersicum) exhibited increased $\mathrm{Na}^{+}$content in roots and leaves as compared to wild type under salt stress, while stems of silenced plants accumulated less $\mathrm{Na}^{+}$than the wild type (Olías et al., 2009). These results prompted a suggestion that SISOS1 possibly functioned in $\mathrm{Na}^{+}$extrusion from the leaf cells back to the xylem stream in order to protect photosynthetic organs (Olías et al., 2009). SOS1 also appears to have several other cellular functions that are not directly related to $\mathrm{Na}^{+}$-homeostasis. A recent study using fluorescent probes reported that the loss of the functional AtSOS1 gene resulted in altered $\mathrm{pH}$ homeostasis, both in the cytosol and the vacuole of root cells, probably due to the alteration in plasma membrane $\mathrm{H}^{+}$flux (Shabala et al., 2005; Oh et al., 2010). In addition, the fragmentation of vacuoles and deficiencies in endocytosis have also been reported in atsos 1 mutants under salinity stress (Oh et al., 2010).

\section{HKT TRANSPORTERS}

The gene encoding high-affinity $\mathrm{K}^{+}$transporter, HKT1 was first identified in the wheat genome by functional complementation screening for genes that rescue the deficiency of
TRK1 and TRK2-mediated $\mathrm{K}^{+}$uptake activity in S. cerevisiae mutants (Schachtman and Schroeder, 1994). HKT1 belongs to the $\mathrm{Trk} / \mathrm{Ktr} / \mathrm{HKT}$-type $\mathrm{K}^{+}$transporter superfamily found in microorganisms, plant cells, and parasites (Gaber et al., 1988; Ko and Gaber, 1988; Dosch et al., 1991; Schlösser et al., 1991; Schachtman and Schroeder, 1994; Nakamura et al., 1998; Mosimann et al., 2010). The further study on HKT1 revealed that the wheat HKT1 (TaHKT2;1) showed $\mathrm{Na}^{+} / \mathrm{K}^{+}$co-transport activity at high $\mathrm{Na}^{+}$as compared to $\mathrm{K}^{+}$in extracellular compartment (Rubio et al., 1995; Gassmann et al., 1996). The $\mathrm{Na}^{+}$-dependent activation of $\mathrm{K}^{+}$uptake was later found in KtrAB in Vibrio alginolyticus (Nakamura et al., 1998), and KtrABE in cyanobacteria Synechosytis PCC 6803 as well (Matsuda et al., 2004). TbHKT1 in Trypanosoma brucei (Mosimann et al., 2010) and TsHKT1;2 in T. salsuginea (Ali et al., 2012) showed higher selectivity for $\mathrm{K}^{+}$over $\mathrm{Na}^{+}$. On the other hand, a strong $\mathrm{Na}^{+}$selective transport activity was found in AtHKT1;1 isolated from Arabidopsis (Uozumi et al., 2000). $\mathrm{Na}^{+}$selectivity was also seen in HKTs from other species including Eucalyptus camaldulensis and rice (Fairbairn et al., 2000; Horie et al., 2001).

An array of biochemical approaches including bacterial alkaline phosphatase-fusion analysis, glycosylation scanning, and immunofluorescence detection, revealed that AtHKT1 contains eight transmembrane domains that correspond to fourfold bacterial simple $\mathrm{K}^{+}$channels consisting of transmembrane-poretransmembrane motifs, and $\mathrm{N}$ - and C-termini that face the cytoplasm (Kato etal., 2001). Trk/Ktr/HKT-type transporters appear to have evolutional correlation with the ion-conducting regions of $\mathrm{K}^{+}$channels, $\mathrm{Na}^{+}$channels, $\mathrm{Ca}^{2+}$ channels, and $\mathrm{Kdp}$ type $\mathrm{K}^{+}$pumps (Durell et al., 1999; Durell and Guy, 1999; Uozumi and Dreyer, 2012). The glycine of the $\mathrm{K}^{+}$ion selective filter in the four pore domains of Trk/Ktr/HKT-type transporters is analogous to the first glycine in the GYG signature sequence (Mäser et al., 2002b; Tholema et al., 2005; Uozumi and Dreyer, 2012). In AtHKT1, the serine in the first pore region in AtHKT1 is substituted for glycine, while the following three glycine residues are conserved. Replacement of the serine by glycine in AtHKT1 led to the increase of $\mathrm{K}^{+}$transport activity, which strongly suggested that AtHKT1 functions as a $\mathrm{Na}^{+}$selective transporter rather than a $\mathrm{K}^{+}$transport system. Based on the relationship of Gly/Ser and $\mathrm{Na}^{+} / \mathrm{K}^{+}$selectivity in $\mathrm{Trk} / \mathrm{Ktr} / \mathrm{HKT}$-type transporters in combination with sequence alignments, HKTs were categorized into two major groups (Platten et al., 2006). The conserved arginine in the middle of the last transmembrane domain of Trk/Ktr/HKT-type transporters, which is not conserved in $\mathrm{K}^{+}$channels, is one of the determinants of "transporter" activity but not "channel" activity (Kato et al., 2007). The gating of the ion transport is controlled by the sixth transmembrane in KtrB of $V$. alginolyticus (Hänelt et al., 2010a,b). This structure-function relationship is supported by the crystal structure of a TrkH from Vibrio parahaemolyticus (Cao et al., 2011).

A long-term exposure of a plant to $\mathrm{Na}^{+}$in soil will translocate $\mathrm{Na}^{+}$from the root to above ground tissue (Mäser et al., 2002a). AtHKT1 may participate in the $\mathrm{Na}^{+}$uptake and $\mathrm{Na}^{+}$circulation in plant body. The analysis of AtHKT1 gene expression by the use of the GUS reporter system showed that AtHKT1 was expressed in vascular tubes (Mäser et al., 2002a; Berthomieu et al., 2003). 
This detailed observation, in combination with immunoelectron microscopic detection, showed that AtHKT1;1 resides at the plasma membrane of xylem parenchyma cells and phloem tissues (Berthomieu et al., 2003; Sunarpi et al., 2005). Likewise, one of the rice HKTs was present in xylem parenchyma cells (Ren et al., 2005). The sas2 (sodium over-accumulation in shoots) mutant exhibited increased $\mathrm{Na}^{+}$accumulation in aerial organs and decreased it in roots (Berthomieu et al., 2003). Taken together, the hypothetical model proposed here to explain the physiological role of AtHKT1 is that AtHKT1 works by unloading $\mathrm{Na}^{+}$from shoot xylem sap of Arabidopsis in the presence of high salinity and for recirculation of shoot to root (Figure 1; Mäser et al., 2002a; Berthomieu et al., 2003; Sunarpi et al., 2005).

Some transcriptional regulatory elements have been identified in the AtHKT1 promoter. The tandem repeat regions found far from the AtHKT1 initiation codon (approximately -3.9 to $-5.3 \mathrm{~kb}$ ) were responsible for the expression in roots (Rus et al., 2006). The second-half of the repeat sequence, which was located in the $3^{\prime}$ region of two repeat sequences, acted as enhancer elements for AtHKT1 expression (Baek et al., 2011). Reduction of the expression in the root by the inactivation of the repeat sequence induced overaccumulation of $\mathrm{Na}^{+}$in the shoot (Rus et al., 2006). In accordance with this result, the engineered root stele-specific AtHKT1-overexpressor reduced salt content in the shoot, whereas AtHKT1 expression driven by the $35 S$ promoter in whole plant resulted in salt hypersensitivity (Møller et al., 2009). The putative highly methylated sequence (250 bp) was found $2.6 \mathrm{~kb}$ upstream from the initiation codon of AtHKT1. It is believed that this region

\section{REFERENCES}

Agarwal, P. K., Shukla, P. S., Gupta K., and Jha, B. (2013). Bioengineering for salinity tolerance in plants: state of art. Mol. Biotechnol. 54, 102-123. doi: 10.1007/s12033-0129538-3

Ali, Z., Park, H. C., Ali, A., Oh, D. H., Aman, R., Kropornicka, A., et al. (2012). TsHKT1;2, a HKT1 homolog from the extremophile Arabidopsis relative Thellungiella salsuginea, shows $\mathrm{K}^{+}$specificity in the presence of NaCl. Plant Physiol. 158, 1463-1474. doi: 10.1104/pp.111. 193110

An, R., Chen, Q. J., Chai, M. F., Lu, P. L., Su, Z., Qin, Z. X., et al. (2007). AtNHX8, a member of the monovalent cation: proton antiporter- 1 family in Arabidopsis thaliana, encodes a putative $\mathrm{Li} / \mathrm{H}$ antiporter. Plant $\mathrm{J}$. 49, 718-728. doi: 10.1111/j.1365313X.2006.02990.x

Apse, M. P., Aharon, G. S., Snedden, W. A., and Blumwald, E. (1999). Salt tolerance conferred by overexpression of a vacuolar $\mathrm{Na}^{+} / \mathrm{H}^{+}$antiport in Arabidopsis. Science 285, $1256-$ 1258. doi: $10.1126 /$ science.285.5431. 1256

Apse, M. P., and Blumwald, E. (2007). $\mathrm{Na}^{+}$transport in plants. FEBS Lett.
581, 2247-2254. doi: 10.1016/j. febslet.2007.04.014

Apse, M. P., Sottosanto, J. B., and Blumwald, E. (2003). Vacuolar cation $/ \mathrm{H}^{+}$exchange, ion homeostasis, and leaf development are altered in a T-DNA insertional mutant of AtNHX1, the Arabidopsis vacuolar $\mathrm{Na}^{+} / \mathrm{H}^{+}$antiporter. Plant J. 36, 229239. doi: 10.1046/j.1365-313X.2003. 01871.x

Barragan, V., Leidi, E. O., Andres, Z., Rubio, L., Luca, A. D., Fernandez, J. A., etal. (2012). Ion exchangers NHX1 and NHX2 mediate active potassium uptake into vacuoles to regulate cell turgor and stomatal function in Arabidopsis. Plant Cell 24, 1127-1142. doi: 10.1105/tpc.111. 095273

Bassil, E., Coku, A., and Blumwald, E. (2012). Cellular ion homeostasis: emerging roles of intracellular $\mathrm{NHX} \mathrm{Na}{ }^{+} / \mathrm{H}^{+}$antiporters in plant growth and development. J. Exp. Bot. 63, 5727-5740. doi: 10.1093/jxb/ ers250

Bassil, E., Ohto, M. A., Esumi, T. Tajima, H., Zhu, Z., Cagnac, O., et al. (2011a). The Arabidopsis intracellular $\mathrm{Na}^{+} / \mathrm{H}^{+}$antiporters $\mathrm{NHX} 5$ and NHX6 are endosome associated and necessary for plant growth and

is a potential small RNA target site and the methylation in this region may control the expression of $A t H K T 1$ at a low level (Baek et al., 2011).

\section{CONCLUDING REMARKS}

Almost two decades of extensive molecular studies have clearly established the involvement of NHX, SOS1, and HKT transporters in plant salt tolerance. The genes encoding some of these transporters have since been successfully utilized as genetic tools for enhancing salt tolerance of model and crop plants. Recent advancements have also provided evidence on the involvement of these transporters in other vital cellular processes. This indicates the possibility that further enhancement of salt tolerance by overexpression of any of the above-mentioned genes might reach its limit due to excessive perturbation of related cellular and physiological processes. A much broader and profound understanding of the molecular properties, regulations, and cellular/physiological functions of $\mathrm{Na}^{+}$-transporters, may provide further insight into the development of efficient strategies for the engineering of "super salt-tolerant" crop plants and therefore progress in this research field is highly anticipated.

\section{ACKNOWLEDGMENTS}

We thank Mario Fon for the proofreading and editing the manuscript. This work was supported by Grants-in-Aid for Scientific Research from Japan Society for the Promotion of Science (24102504, 24580135, and 25292055).

development. Plant Cell 23, 224-239. doi: $10.1105 /$ tpc. 110.079426

Bassil, E., Tajima, H., Liang, Y. C., Ohto, M. A., Ushijima, K., Nakano, R., et al. (2011b). The Arabidopsis $\mathrm{Na}^{+} / \mathrm{H}^{+}$ antiporters NHX1 and NHX2 control vacuolar $\mathrm{pH}$ and $\mathrm{K}^{+}$homeostasis to regulate growth, flower development, and reproduction. Plant Cel 23, 3482-3492. doi: 10.1105/tpc.111. 089581

Baek, D., Jiang, J., Chung, J. S., Wang, B., Chen, J., Xin, Z., et al. (2011). Regulated AtHKT1 gene expression by a distal enhancer element and DNA methylation in the promoter plays an important role in salt tolerance. Plant Cell Physiol. 52, 149-161. doi: 10.1093/pcp/ pcq182

Berthomieu, P., Conéjéro, G., Nublat, A., Brackenbury, W. J., Lambert, C., Savio, C., et al. (2003). Functional analysis of AtHKT1 in Arabidopsis shows that $\mathrm{Na}^{+}$recirculation by the phloem is crucial for salt tolerance. EMBO J. 22, 2004-2014. doi: $10.1093 / \mathrm{emboj} / \mathrm{cdg} 207$

Blumwald, E. (2000). Sodium transport and salt tolerance in plants. Curr. Opin. Cell Biol. 12, 431434. doi: 10.1016/S0955-0674(00) 00112-5
Blumwald, E., Aharon, G. S., and Apse, M. P. (2000). Sodium transport in plant cells. Biochim. Biophys. Acta 1465, 140-151. doi: 10.1016/S00052736(00)00135-8

Brett, C. L., Donowitz, M., and Rao, R. (2005). Evolutionary origins of eukaryotic sodium/proton exchangers. Am. J. Physiol. Cell Physiol. 288, C223-C239. doi: 10.1152/ajpcell.00360.2004

Cao, Y., Jin, X., Huang, H., Derebe, M. G., Levin, E. J., Kabaleeswaran, V., et al. (2011). Crystal structure of a potassium ion transporter, TrkH. Nature 471, 336-340. doi: 10.1038/ nature 09731

Ding, L., and Zhu, J. K. (1997). Reduced $\mathrm{Na}^{+}$uptake in the $\mathrm{NaCl}-$ hypersensitive sos1 mutant of Arabidopsis thaliana. Plant Physiol. 113, 795-799. doi: 10.1104/pp.113. 3.795

Dosch, D. C., Helmer, G. L., Sutton, S. H., Salvacion, F. F., and Epstein, W. (1991). Genetic analysis of potassium transport loci in Escherichia coli: evidence for three constitutive systems mediating uptake potassium. $J$. Bacteriol. 173, 687-696.

Durell, S. R., and Guy, H. R. (1999). Structural models of the KtrB, TrkH, and Trk1,2 symporters 
based on the structure of the KcsA $\mathrm{K}^{+}$channel. Biophys. J. 77, 789807. doi: 10.1016/S0006-3495(99) 76932-8

Durell, S. R., Hao, Y., Nakamura, T., Bakker, E. P., and Guy, $\mathrm{H}$. R. (1999). Evolutionary relationship between $\mathrm{K}^{+}$channels and symporters. Biophys. J. 77, 775788. doi: 10.1016/S0006-3495(99) 76931-6

Fairbairn, D. J., Liu, W., Schachtman, D. P., Gomez-Gallego, S., Day, S. R. and Teasdale, R. D. (2000). Characterisation of two distinct HKT1-like potassium transporters from Eucalyptus camaldulensis. Plant Mol. Biol. 43, 515-525. doi: 10.1023/A:100649 6402463

Flowers, T. J., and Läuchli, A. (1983). "Sodium versus potassium: substitution and compartmentation," in Encyclopedia of Plant Physiology 15B, New Series, Inorganic Plant Nutrition, eds A. Läuchli and R. A. Bieleski (Berlin: Springer), 651-681.

Fukada-Tanaka, S., Inagaki, Y., Yamaguchi, T., Saito, N., and Iida, S. (2000). Colourenhancing protein in blue petals. Nature 407, 581. doi: 10.1038/ 35036683

Gaber, R. F., Styles, C. A., and Fink, G. R. (1988). TRK1 encodes a plasma membrane protein required for highaffinity potassium transport in Saccharomyces cerevisiae. Mol. Cell. Biol. 8, 2848-2859.

Gassmann, W., Rubio, F., and Schroeder, J. I. (1996). Alkali cation selectivity of the wheat root high-affinity potassium transporter HKT1. Plant J. 10, 869882. doi: 10.1046/j.1365-313X.1996. 10050869.x

Gruwel, M. L. H., Rauw, V. L., Loewen, M., and Abrams, S. R. (2001). Effects of sodium chloride on plant cells: a $31 \mathrm{P}$ and $23 \mathrm{Na}$ NMR system to study salt tolerance. Plant Sci. 160, 785794. doi: $10.1016 / \mathrm{S} 0168-9452(00)$ 00424-6

Hall, J. L., and Flowers, T. J. (1973). The effect of salt on protein synthesis in the halophyte Suaeda maritima. Planta 110, 361-368. doi: 10.1007/ BF00387064

Hänelt, I., Löchte, S., Sundermann, L., Elbers, K., Vor der Brüggen, M., and Bakker, E. P. (2010a). Gain of function mutations in membrane region $\mathrm{M} 2 \mathrm{C} 2$ of $\mathrm{KtrB}$ open a gate controlling $\mathrm{K}^{+}$transport by the KtrAB system from Vibrio alginolyticus. J. Biol. Chem 285, 10318-10327. doi: 10.1074/jbc. M109.089870
Hänelt, I., Wunnicke, D., MüllerTrimbusch, M., Vor der Brüggen, M. Kraus, I., Bakker, E. P., et al. (2010b). Membrane region $\mathrm{M} 2 \mathrm{C} 2$ in subunit $\mathrm{KtrB}$ of the $\mathrm{K}^{+}$uptake system KtrAB from Vibrio alginolyticus forms a flexible gate controlling $\mathrm{K}^{+}$flux: an electron paramagnetic resonance study. J. Biol. Chem. 285, 28210-28219. doi: 10.1074/jbc.M110.139311

Hauser, F., and Horie, T. (2010) A conserved primary salt tolerance mechanism mediated by HKT transporters: a mechanism for sodium exclusion and maintenance of high $\mathrm{K}^{+} / \mathrm{Na}^{+}$ratio in leaves during salinity stress. Plant Cell Environ. 33, 552565. doi: 10.1111/j.1365-3040.2009. 02056.x

Horie, T., Yoshida, K., Nakayama, H., Yamada, K., Oiki, S., and Shin myo, A. (2001). Two types of HKT transporters with different properties of $\mathrm{Na}^{+}$and $\mathrm{K}^{+}$transport in Oryza sativa. Plant J. 27, 129 138. doi: 10.1046/j.1365-313x.2001. 01077.x

Huertas, R., Rubio, L., Cagnac, O. García-Sánchez, M. J., Alché, J. D. Venema, K., et al. (2013). The $\mathrm{K}^{+} / \mathrm{H}^{+}$ antiporter LeNHX2 increases salt tolerance by improving $\mathrm{K}^{+}$homeostasis in transgenic tomato. Plant Cell Environ. doi: 10.1111/pce.12109 [Epub ahead of print].

Kato, N., Akai, M., Zulkifli, L., Matsuda, N., Kato, Y., Goshima, S., et al. (2007). Role of positively charged amino acids in the M2D transmembrane helix of Ktr/Trk/HKTtype cation transporters. Channels 1 161-171.

Kato, Y., Sakaguchi, M., Mori, Y., Saito, K., Nakamura, T., Bakker, E. P., etal. (2001). Evidence in support of a four transmembrane-poretransmembrane topology model for the Arabidopsis thaliana $\mathrm{Na}^{+} / \mathrm{K}^{+}$ translocating AtHKT1 protein, a member of the superfamily of $\mathrm{K}^{+}$ transporters. Proc. Natl. Acad. Sci. USA. 98, 6488-6493. doi: 10.1073/ pnas. 101556598

Ko, C. H., and Gaber, R. F. (1988) TRK1 and TRK2 encode structurally related $\mathrm{K}^{+}$transporters in Saccharomyces cerevisiae. Mol. Cell. Biol. 11 4266-4273.

Leidi, E. O., Barragán, V., Rubio L., El-Hamdaoui, A., Ruiz, M. T., Cubero, B., et al. (2010). The AtNHX1 exchanger mediates potassium compartmentation in vacuoles of transgenic tomato. Plant $J$. 61, 495-506. doi: 10.1111/j.1365313X.2009.04073.x

Martínez-Atienza, J., Jiang, X., Garciadeblas, B., Mendoza, I., Zhu, J.
K., Pardo, J. M., et al. (2007). Conservation of the salt overly sensitive pathway in rice. Plant Physiol. 143, 1001-1012. doi: 10.1104/pp.106. 092635

Mäser, P., Eckelman, B., Vaidyanathan, R., Fairbain, D. J., Kubo, M. Yamagami, M., etal. (2002a). Altered shoot/root $\mathrm{Na}^{+}$distribution and bifurcating salt sensitivity in Arabidopsis by genetic disruption of the $\mathrm{Na}^{+}$transporter AtHKT1. FEBS Lett. 531, 157161. doi: 10.1016/S0014-5793(02) 03488-9

Mäser, P., Hosoo, Y., Goshima, S., Horie, T., Eckelman B., Yamada, K., et al. (2002b). Glycine residues in potassium channel-like selectivity filters determine potassium selectivity in four-loop-per-subunit HKT transporters from plants. Proc. Natl. Acad. Sci. USA. 99, 6428-6433. doi: 10.1073/pnas. 082123799

Matsuda, N., Kobayashi, H., Katoh, H., Ogawa, T., Futatsugi, L., Nakamura, T., etal. (2004). $\mathrm{Na}^{+}$ dependent $\mathrm{K}^{+}$uptake $\mathrm{Ktr}$ system from the cyanobacterium Syne chocystis sp. PCC 6803 and its role in the early phases of cell adaptation to hyperosmotic shock. J. Biol. Chem. 279, 54952-54962. doi: 10.1074/jbc. M407268200

Møller, I. S., Gilliham, M., Jha, D., Mayo, G. M., Roy, S. J. Coates, J. C., et al. (2009). Shoot $\mathrm{Na}^{+}$exclusion and increased salinity tolerance engineered by cell typespecific alteration of $\mathrm{Na}^{+}$transport in Arabidopsis. Plant Cell 21, 2163-2178. doi: 10.1105/tpc.108. 064568

Mosimann, M., Goshima, S., Wenzler, T., Lüscher, A., Uozumi, N., and Mäser, P. (2010). A Trk/HKT-type $\mathrm{K}^{+}$transporter from Trypanosoma brucei. Eukaryot. Cell 9, 539-546. doi: 10.1128/EC 00314-09

Munns, R., and Tester, M. (2008). Mechanisms of salinity tolerance. Annu. Rev. Plant Biol. 59, 651681. doi: 10.1146/annurev.arplant 59.032607 .092911

Murguía, J. R., Bellés, J. M., and Serrano, R. (1995). A salt-sensitive $3^{\prime}\left(2^{\prime}\right), 5^{\prime}$-bisphosphate nucleotidase involved in sulfate activation. Science $267,232-234$. doi: $10.1126 /$ science.7809627

Nakamura, T., Yamamuro, N., Stumpe, S., Tsutomu, U., and Bakker, E. P. (1998). Cloning of the trkAH gene cluster and characterization of the Trk $\mathrm{K}^{+}$-uptake system of Vibrio alginolyticus. Microbiology 144,
2281-2289. doi: 10.1099/00221287144-8-2281

Núñez-Ramírez, R., Sánchez-Barrena, M. J., Villalta, I., Vega, J. F., Pardo, J. M., Quintero, F. J., et al. (2012). Structural insights on the plant salt-overly-sensitive 1 (SOS1) $\mathrm{Na}^{+} / \mathrm{H}^{+}$antiporter. J. Mol. Biol. 424, 283-294. doi: 10.1016/j.jmb.2012. 09.015

Oh, D. H., Leidi, E., Zhang, Q., Hwang, S. M., Li, Y., Quintero, F. J., etal. (2009). Loss of halophytism by interference with SOS1 expression. Plant Physiol. 151, 210-222. doi: 10.1104/pp.109. 137802

Oh, D. H., Lee, S. Y., Bressan, R. A., Yun, D. J., and Bohnert, H. J. (2010). Intracellular consequences of SOS1 deficiency during salt stress. J. Exp. Bot. 61, 1205-1213. doi: 10.1093/jxb/ erp391

Okazaki, Y., Kikuyama, M., Hiramoto, Y., and Iwasaki, N. (1996). Shortterm regulation of cytosolic $\mathrm{Ca}^{2+}$, cytosolic $\mathrm{pH}$ and vacuolar $\mathrm{pH}$ under $\mathrm{NaCl}$ stress in the charophyte alga Nitellopsis obtusa. Plant Cell Environ. 19, 569576. doi: 10.1111/j.1365-3040. 1996.tb00390.x

Olías, R., Eljakaoui, Z., Li, J., De Morales, P. A., Marín-Manzano, M. C., Pardo, J. M., etal. (2009). The plasma membrane $\mathrm{Na}^{+} / \mathrm{H}^{+}$ antiporter SOS1 is essential for salt tolerance in tomato and affects the partitioning of $\mathrm{Na}^{+}$between plant organs. Plant Cell Environ. 32, 904916. doi: 10.1111/j.1365-3040.2009. 01971.x

Pardo, J. M., Cubero, B., Leidi, E. O., and Quintero, F. J. (2006). Alkali cation exchangers: roles in cellular homeostasis and stress tolerance. J. Exp. Bot. 57, 1181-1199. doi: 10.1093/jxb/ erj114

Platten, J. D., Cotsaftis, O., Berthomieu, P., Bohnert, H., Davenport, R. J., Fairbairn, D. J., etal. (2006). Nomenclature for HKT transporters, key determinants of plant salinity tolerance. Trends Plant Sci. 11, 372-374. doi: 10.1016/j.tplants.2006. 06.001

Qi, Z., and Spalding, E. P. (2004). Protection of plasma membrane $\mathrm{K}^{+}$ transport by the salt overly sensitive $1 \mathrm{Na}^{+}-\mathrm{H}^{+}$antiporter during salinity stress. Plant Physiol. 136, 2548-2555. doi: 10.1104/pp.104. 049213

Qiu, Q. S. (2012). Plant and yeast NHX antiporters: roles in membrane trafficking. J. Integr. Plant Biol. 54, 66-72. doi: 10.1111/j.17447909.2012.01097.x 
Qiu, Q. S., Barkla, B. J., Vera-Estrella, R., Zhu, J. K., and Schumaker, K. S. (2003). $\mathrm{Na}^{+} / \mathrm{H}^{+}$exchange activity in the plasma membrane of Arabidopsis. Plant Physiol. 132, 1041-1052. doi: 10.1104/pp.102. 010421

Qiu, Q. S., Guo, Y., Dietrich, M. A., Schumaker, K. S., and Zhu, J. K. (2002). Regulation of SOS1, a plasma membrane $\mathrm{Na}^{+} / \mathrm{H}^{+}$exchanger in Arabidopsis thaliana, by SOS2 and SOS3. Proc. Natl. Acad. Sci. USA. 99, 8436-8441. doi: 10.1073/pnas. 122224699

Quan, R., Lin, H., Mendoza, I., Zhang, Y., Cao, W., Yang, Y., et al. (2007). SCABP8/CBL10, a putative calcium sensor, interacts with the protein kinase SOS2 to protect Arabidopsis shoots from salt stress. Plant Cell 19, 1415-1431. doi: 10.1105/tpc.106. 042291

Quintero, F. J., Martinez-Atienza, J., Villalta, I., Jiang, X., Kim, W. Y., Ali, Z., et al. (2011). Activation of the plasma membrane $\mathrm{Na} / \mathrm{H}$ antiporter salt-overly-sensitive 1 (SOS1) by phosphorylation of an auto-inhibitory C-terminal domain. Proc. Natl. Acad. Sci. USA. 108, 2611-2616. doi: 10.1073/pnas. 1018921108

Ren, Z. H., Gao, J. P., Li, L. G., Cai, X. L., Huang, W., Chao, D. Y., et al. (2005). A rice quantitative trait locus for salt tolerance encodes a sodium transporter. Nat. Genet. 37, 1141-1146. doi: 10.1038/ ng1643

Rodríguez-Rosales, M. P., Gálvez, F. J., Huertas, R., Aranda, M. N., Baghour, M., Cagnac, O., et al. (2009). Plant NHX cation/proton antiporters. Plant Signal. Behav. 4, 265-276. doi: 10.4161/psb.4.4. 7919

Rodríguez-Rosales, M. P., Jiang, X. J., Gálvez, F. J., Aranda, M. N., Cubero, B., and Venema, K. (2008). Overexpression of the tomato $\mathrm{K}^{+} / \mathrm{H}^{+}$ antiporter LeNHX2 confers salt tolerance by improving potassium compartmentalization. New Phytol. 179, 366-377. doi: 10.1111/j.14698137.2008.02461.x

Rubio, F., Gassmann, W., and Schroeder, J. I. (1995). Sodium-driven potassium uptake by the plant potassium transporter HKT1 and mutations conferring salt tolerance. Science 270 , 1660-1663. doi: 10.1126/science. 270 . 5242.1660

Rus, A., Baxter, I., Muthukumar, B., Gustin, J., Lahner, B., Yakubova, E., etal. (2006). Natural variants of AtHKT1 enhance $\mathrm{Na}^{+}$accumulation in two wild populations of Arabidopsis. PLoS Genet. 2:e210. doi: 10.1371/journal.pgen. 0020210

Säier, M. H. Jr., Tran, C. V., and Barabote, R. D. (2006). TCDB: the transporter classification database for membrane transport protein analyses and information. Nucleic Acids Res. 34, D181-D186. doi: 10.1093/nar/ gkj001

Sato, Y., and Sakaguchi, M. (2005). Topogenic properties of transmembrane segments of Arabidopsis thaliana NHX1 reveal a common topology model of the $\mathrm{Na}^{+} / \mathrm{H}^{+}$ exchanger family. J. Biochem. (Tokyo) 138, 425-431. doi: $10.1093 / \mathrm{jb} /$ mvi132

Schachtman, D. P., and Schroeder, J. I. (1994). Structure and transport mechanism of a high-affinity potassium uptake transporter from higher plants. Nature 370, 655-658. doi: 10.1038/ $370655 \mathrm{a} 0$

Schlösser, A., Kluttig, S., Hamann, A. and Bakker, E. P. (1991). Subcloning, nucleotide sequence, and expression of trkG, a gene that encodes an integral membrane protein involved in potassium uptake via the Trk system of Escherichia coli. J. Bacteriol. 173 3170-3176.

Shabala, L., Cui, T. A., Newman, I. A., and Shabala, S. (2005). Salinity-induced ion flux patterns from the excised roots of Arabidopsis sos mutants. Planta 222, 10411050. doi: 10.1007/s00425-0050074-2

Shi, H., Ishitani, M., Kim, C. and Zhu, J. K. (2000). The Arabidopsis thaliana salt tolerance gene SOS1 encodes a putative $\mathrm{Na}^{+} / \mathrm{H}^{+}$ antiporter. Proc. Natl. Acad. Sci. USA. 97, 6896-6901. doi: 10.1073/pnas. 120170197

Shi, H., Lee, B. H., Wu, S. J., and Zhu, J. K. (2003). Overexpression of a plasma membrane $\mathrm{Na}^{+} / \mathrm{H}^{+}$ antiporter gene improves salt tolerance in Arabidopsis thaliana. Nat. Biotechnol. 21, 81-85. doi: 10.1038/ nbt766

Shi, L. Y., Li, H. Q., Pan, X. P. Wu, G. J., and Li, M. R. (2008). Improvement of Torenia fournieri salinity tolerance by expression of Arabidopsis AtNHX5. Funct. Plant Biol. 35, 185-192 doi: 10.1071/ FP07269

Shi, H., Quintero, F. J., Pardo, J. M., and Zhu, J. K. (2002). The putative plasma membrane $\mathrm{Na}^{+} / \mathrm{H}^{+}$antiporter SOS1 controls long-distance $\mathrm{Na}^{+}$ transport in plants. Plant Cell 14, 465-477. doi: 10.1105/tpc. 010371
Sottosanto, J. B., Gelli, A., and Blumwald, E. (2004). DNA array analyses of Arabidopsis thaliana lacking a vacuolar $\mathrm{Na}^{+} / \mathrm{H}^{+}$antiporter: impact of AtNHX1 on gene expression. Plant J. 40, 752-771. doi: 10.1111/j.1365-313X.2004.02253.x

Sunarpi, H. T., Motoda, J., Kubo, M., Yang, H., Yoda, K., Horie, R., et al. (2005). Enhanced salt tolerance mediated by AtHKT1 transporterinduced $\mathrm{Na}$ unloading from xylem vessels to xylem parenchyma cells. Plant J. 44, 928-938. doi: 10.1111/j.1365-313X.2005.02595.x

Tholema, N., Vor der Brüggen, M. Mäser, P., Nakamura, T., Schroeder, J. I., Kobayashi, H., et al. (2005). All four putative selectivity filter glycine residues in KtrB are essential for high affinity and selective $\mathrm{K}^{+}$uptake by the KtrAB system from Vibrio alginolyticus. J. Biol. Chem. 280, 4114641154. doi: 10.1074/jbc.M50764 7200

Tsugane, K., Kobayashi, K., Niwa, Y., Ohba, Y., Wada, K., and Kobayashi, H. (1999). A recessive Arabidopsis mutant that grows photoautotrophically under salt stress shows enhanced active oxygen detoxification. Plant Cell 11, 1195-1206.

Tsunekawa, K, Shijuku, T. Hayashimoto, M., Kojima, Y., Onai, K., Morishita, M., Ishiura, M., et al. (2009). Identification and characterization of the $\mathrm{Na}^{+} / \mathrm{H}^{+}$ antiporter Nhas3 from the thylakoid membrane of Synechocystis sp. PCC 6803. J. Biol. Chem. 284, 1651316521. doi: 10.1074/jbc.M109. 001875

Uozumi, N., and Dreyer, I. (2012). "Structure-function correlates in plant ion channels," in Comprehensive Biophysics, Vol. 6, Channel Proteins, ed. E. Egelman (Amsterdam: Elsevier BV), 234-245

Uozumi, N., Kim, E. J., Rubio, F., Yamaguchi, T., Muto, S., Tsuboi, A., et al. (2000). The Arabidopsis HKT1 gene homolog mediates inward $\mathrm{Na}^{+}$currents in Xenopus laevis oocytes and $\mathrm{Na}^{+}$uptake in Saccharomyces cerevisiae. Plant Physiol. 122, 1249-1259. doi: 10.1104/pp.122.4. 1249

Uozumi, N., and Schroeder, J. I. (2010). "Ion channels and plant stress: past, present and future," in Ion Channels and Plant Stress Responses, eds V. Demidchik and F. Maathuis (Berlin: Springer), 1-22.

Vera-Estrella, R., Barkla, B. J., GarcíaRamírez, L., and Pantoja, O. (2005). Salt stress in Thellungiella halophila activates $\mathrm{Na}^{+}$transport mechanisms required for salinity tolerance.
Plant Physiol. 139, 1507-1517. doi: 10.1104/pp.105.067850

Wu, S. J., Ding, L., and Zhu, J. K. (1996). SOS1, a genetic locus essential for salt tolerance and potassium acquisition. Plant Cell 8, 617-627.

Xu, H., Jiang, X., Zhan, K., Cheng, X., Chen, X., Pardo, J. M., et al. (2008). Functional characterization of a wheat plasma membrane $\mathrm{Na}^{+} / \mathrm{H}^{+}$antiporter in yeast. Arch. Biochem. Biophys. 473, 8-15. doi: 10.1016/j.abb.2008.02.018

Yamaguchi, T., Aharon, G. S., Sottosanto, J. B., and Blumwald, E. (2005). Vacuolar $\mathrm{Na}^{+} / \mathrm{H}^{+}$antiporter cation selectivity is regulated by calmodulin from within the vacuole in $\mathrm{Ca}^{2+}$ - and $\mathrm{pH}$-dependent manner. Proc. Natl. Acad. Sci. U.S.A. 102, 16107-16112. doi: 10.1073/ pnas.0504437102

Yamaguchi, T., Apse, M. P., Shi, H., and Blumwald, E. (2003). Topological analysis of a plant vacuolar $\mathrm{Na}^{+} / \mathrm{H}^{+}$antiporter reveals a luminal $\mathrm{C}$ terminus that regulates antiporter cation selectivity. Proc. Natl. Acad. Sci. U.S.A. 100, 1251012515. doi: 10.1073/pnas.20349 66100

Yamaguchi, T., and Blumwald, E. (2005). Developing salt tolerant crop plants: challenges and opportunities. Trends Plant Sci. 10, 615-620. doi: 10.1016/j.tplants.2005.10.002

Yamaguchi, T., Fukada-Tanaka, S., Inagaki, Y., Saito, N., YonekuraSakakibara, K., Tanaka, Y., et al. (2001). Genes encoding the vacuolar $\mathrm{Na}^{+} \mathrm{H}^{+}$exchanger and flower coloration. Plant Cell Physiol. 42, 451-461. doi: 10.1093/pcp/pce080

Yang, Q., Chen, Z. Z., Zhou, X. F., Yin, H. B., Li, X. F., Xin, X. F., etal. (2009). Overexpression of SOS (salt overly sensitive) genes increases salt tolerance in transgenic Arabidopsis. Mol. Plant 2, 22-31. doi: 10.1093/mp/ssn058

Yeo, A. R. (1999). Predicting the interaction between the effects of salinity and climate change on crop plants. Sci. Hortic. (Amsterdam) 78, 159174. doi: 10.1016/S0304-4238(98) 00193-9

Zhang, H. H., Hodson, J. N., Williams, J. P., and Blumwald, E. (2001). Engineering salt-tolerant Brassica plants: characterization of yield and seed oil quality in transgenic plants with increased vacuolar sodium accumulation. Proc. Natl. Acad. Sci. U.S.A. 98, 1283212836. doi: 10.1073/pnas. 23147 6498

Zhang, H. X., and Blumwald, E. (2001). Transgenic salt-tolerant 
tomato plants accumulate salt in foliage but not in fruit. Nat. Biotechnol. 19, 765-768. doi: 10.1038/ 90824

Conflict of Interest Statement: The authors declare that the research was conducted in the absence of any commercial or financial relationships that could be construed as a potential conflict of interest.

Received: 20 August 2013; paper pending published: 11 September 2013; accepted: 27 September 2013; published online: 17 October 2013.

Citation: Yamaguchi T, Hamamoto S and Uozumi N (2013) Sodium transport system in plant cells. Front. Plant Sci. 4:410. doi: 10.3389/fpls.2013.00410

This article was submitted to Plant Physiology, a section of the journal Frontiers in Plant Science.

Copyright (c) 2013 Yamaguchi, Hamamoto and Uozumi. This is an open-access article distributed under the terms of the Creative Commons
Attribution License (CC BY). The use, distribution or reproduction in other forums is permitted, provided the original author(s) or licensor are credited and that the original publication in this journal is cited, in accordance with accepted academic practice. No use, distribution or reproduction is permitted which does not comply with these terms. 